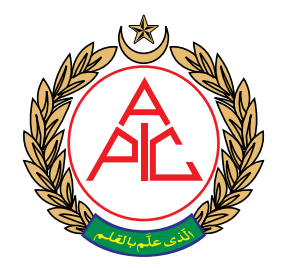

\title{
A comparison of bupivacaine with or without tramadol in caudal epidural block for postoperative caudal analgesia in children undergoing lower abdominal surgery under general anesthesia
}

\author{
Noor Un Nisa, Saqib Butt, Hasham Khan, Ghulam Mustafa
}

\begin{abstract}
Noor Un Nisa, Senior Registrar, Department of Anesthesiology, Shaikh Zayad Hospital, Lahore (Pakistan); E-mail: noorunnisa53@yahoo.com Saqib Butt, Assistant Consultant, Department of Anesthesiology, Islamabad Medical \& Dental College, Islamabad (Pakistan); E-mail: drsaqibbutt@hotmail.com Hasham Khan, Senior Registrar Urology, Akbar Niazi Teaching Hospital, Islamabad (Pakistan), E-mail: Hasham.khan86@ yahoo.com

Ghulam Mustafa, Islamabad Medical \& Dental College, Islamabad (Pakistan); E-mail: sulehrionline99@hotmail.com Correspondence: Dr Noor Un Nisa, 344-N, Phase 8, DHA, Lahore (Pakistan)

E-mail: noorunnisa53@yahoo. com
\end{abstract}

Received: 2 September 2019,

Reviewed: 3, 4 September 2019,

Revised: 7 September, 2019

Reviewed: 17 September 2019,

Accepted: 18 September 2019

\begin{abstract}
\section{Background and Objective:}

Millions of children receive sedative, anesthetic and analgesic drugs for surgery worldwide. Caudal epidural block with bupivacaine is widely used for perioperative analgesia in children undergoing surgeries under general anesthesia. Current study aims to determine postoperative pain relief and side effects due to caudally administered $0.25 \%$ bupivacaine $(0.5-1 \mathrm{ml} / \mathrm{kg})$ alone and a combination of $0.25 \%$ bupivacaine $(0.5-1$ $\mathrm{ml} / \mathrm{kg}$ ) with tramadol $(1 \mathrm{mg} / \mathrm{kg})$.
\end{abstract}

Methodology: A randomized clinical trial was conducted at department of Anesthesiology, Shaikh Zayed Hospital, Lahore. Study duration was 1 year and 6 months (February 2015-August 2016). A sample size of 108 patients was calculated using WHO calculator. Non probability consecutive sampling was used. Patients were randomly divided into two groups; Group B was given inj. bupivacaine $0.25 \%$ while Group BT received a combination of $0.25 \%$ bupivacaine $(0.5-1 \mathrm{ml} / \mathrm{kg})$ with tramadol $(1 \mathrm{mg} / \mathrm{kg})$. Patients were observed for sedation score, FLACC pain score and adverse effects in both interventional groups. Data were analyzed using SPSS version 22. Student's T-test was applied on data. P-value $\leq 0.05$ was considered significant.

Results: Total 108 patients were included in the study (1:1 randomization). Mean age of patients was $6.41 \pm 1.77 \mathrm{y}$. There were $92(85.2 \%)$ male and $16(14.8 \%)$ female children. Mean sedative scores $(p=0.00)$ and mean FLACC pain scores $(p=0.000)$ were significantly lower in bupivacaine tramadol group as compared to bupivacaine group. However, bupivacaine group had more adverse effects as compared to combination of bupivacaine and tramadol group.

Conclusion: Caudal epidural with a combination of $0.25 \%$ bupivacaine $(0.5-1 \mathrm{ml} / \mathrm{kg})$ with tramadol $(1 \mathrm{mg} / \mathrm{kg})$ has high postoperative analgesic efficacy and limited adverse effects as compared to $0.25 \%$ bupivacaine alone in children undergone general anesthesia for lower abdominal surgery.

\section{Key words:}

Caudal epidural block; Bupivacaine; Tramadol; Analgesia; FLACC score; Sedation score

Citation: Nisa NU, Butt S, Khan H, Mustafa G. A comparison of bupivacaine with or without tramadol in caudal epidural block for postoperative caudal analgesia in children undergoing lower abdominal surgery under general anesthesia. Anesth pain \& intensiv care 2019;23(3):279-283 
tramadol-bupivacaine for pediatric caudal bloc

\section{INTRODUCTION}

Millions of children receive sedative, anesthetic and analgesic drugs for surgery, worldwide. ${ }^{1}$ Pediatric organ systems are highly sensitive to anesthetic depressant effects leading towards more than 10 folds increase in peri-operative mortality and morbidity. ${ }^{2}$ Over the years, several analgesic routes have been tried for postoperative analgesia. Some of these were associated with significant pain relief and reduced general anesthesia requirement without increasing relative side effects. Caudal blocks have been found useful in several infra-umbilical operations; and have been associated with significant postoperative / intraoperative analgesia among children. ${ }^{3}$

Pain is an unpleasant (subjective) sensation. This sensation could not be expressed by children and depends upon care givers to identify it. Pain in children leads to agony, discomfort, feeding disturbances, irritability and restlessness. Caudal epidural block with bupivacaine is a common technique for pain relief in children. Moreover, analgesia provided by a single caudal injection of bupivacaine is usually of short duration (2-4 h). Duration of analgesia could be increased by addition of opioids in epidural space, ${ }^{4}$ although addition of opioids has been associated with several complications in children, including high risk of respiratory depression. ${ }^{5}$

Tramadol (synthetic analogue of codeine) is a mixture of $(+,-)$ enantiomers. Enantiomers of tramadol have significant affinity for $\mu$-receptor of opioid (inhibits serotonin uptake) and potent norepinephrine inhibitors (positive and negative respectively). More interestingly, these factors lead to enhanced analgesic potency (equal to meperidine) of opioids without adverse effects. Caudal epidural block with tramadol plus bupivacaine, increases postoperative analgesic duration up to 4-8 hours. Evidence exist that optimum tramadol dose for caudal epidural block is $1-2 \mathrm{mg} / \mathrm{kg}$. The analgesic action of tramadol is usually inhibited by opioid antagonist naloxone as compared to other opioids. The process suggests another mechanism of action. This mechanism was demonstrated through monoaminergic activity (associated with noradrenaline and serotonin reuptake inhibition), blocking nociceptive impulses at spinal level and leading towards significant analgesia. ${ }^{6}$

A similar study reported that duration of analgesia was longer $(12 \pm 0.9 \mathrm{~h})$ with bupivacaine $0.25 \%(0.75$ $\mathrm{ml} / \mathrm{kg})$ in combination with tramadol $(2 \mathrm{mg} / \mathrm{kg})$ as compared to other groups. No significant changes were found in oxygen saturation, heart rate and arterial pressure in different groups. No adverse effects were found. ${ }^{7}$ Another similar study reported that bupivacaine $0.25 \%$ with tramadol is associated with longer duration of analgesia and lower postoperative pain scores as compare to bupivacaine alone $(\mathrm{p}=$ $0.02)^{8,9}$ Several studies reported that caudal tramadol leads to good quality analgesia approximately for 10.7 h.

Limited data is available on use of bupivacaine combination with tramadol in Pakistan. Current study aimed to determine postoperative pain relief and side effects due to caudally administered $0.25 \%$ bupivacaine $(0.5-1 \mathrm{ml} / \mathrm{kg})$ alone and combination of $0.25 \%$ bupivacaine $(0.5-1 \mathrm{ml} / \mathrm{kg})$ with tramadol $(1 \mathrm{mg} /$ $\mathrm{kg})$.

\section{METHODOLOY}

This randomized, clinical trial was conducted at Department of Anesthesiology, Shaikh Zayed Hospital, Lahore. Study duration was 1.5 y (February 2015-August 2016). A sample size of 108 patients was calculated with $\mathrm{P} 1=13.3 \%, \mathrm{P} 26.6 \%{ }^{10}, 95 \%$ Confidence interval, and margin of error $8 \%$ using WHO calculator. Non probability consecutive sampling was used for patient's selection. Inclusion criteria was; age 5-10 y, patients with American Society of Anesthesiologists classification I and II, both genders and patients undergoing elective lower abdominal surgery. Patients with history of allergy to bupivacaine and tramadol, anticoagulant therapy, history of bleeding diathesis and whose parents refused epidural were excluded from the study. Ethical approval was taken from ethical review board of relevant hospital. Consent forms were taken from the parents. Patients were randomly divided into two groups. Group B received caudal block with $(0.5-1 \mathrm{ml} / \mathrm{kg})$ of $0.25 \%$ bupivacaine, while Group BT received $(0.5-1 \mathrm{ml} / \mathrm{kg}) \mathrm{ml} / \mathrm{kg}$ of $0.25 \%$ bupivacaine plus tramadol $1 \mathrm{mg} / \mathrm{kg}$. Patients were assessed from 30 min to $1,4,8,12$ and $24 \mathrm{~h}$. Patients were observed for sedation scores, postoperative pain scores (FLACC scale) and side effects. Data were analyzed using SPSS version 22. Frequency and percentages were calculated for qualitative data while mean \pm standard deviation was calculated for quantitative data. Student's T test was applied for comparison of FLACC and sedation scores in both groups.

\section{RESULTS}

A total of 108 patients were included in the study (1:1 randomization). Mean age of patients was $6.7 \pm 1.8 \mathrm{y}$ vs. $6 \pm 1.5 \mathrm{y}$ in Group B and Group BT respectively. There were $92(85.2 \%)$ males and $16(14.8 \%)$ females. Mean weight of patients was $16.22 \pm 5.0 \mathrm{~kg}$. Mean weight of patients in Group B was $18.22 \pm 5.32 \mathrm{~kg}$ while in Group BT was $14.22 \pm 3.74 \mathrm{~kg}$. Mean duration of surgery was $39.44 \pm 16.9 \mathrm{~min}$. Mean duration of surgery in Group B was $34.72 \pm 11.0$ min while in Group BT mean duration of surgery was $44.17 \pm$ 
$20.29 \mathrm{~min}$. Mean duration of analgesia was $10 . \pm 4.1 \mathrm{~h}$ vs. $11.3 \pm 4.5 \mathrm{~h}$ in Group A vs. Group B respectively. Hemodynamic and respiratory parameters remained stable. Sedation scores were significantly higher in Group B at 30 min, 1, 4, 8, 12 and $24 \mathrm{~h}$ after operation as compared to Group BT $(\mathrm{p}=0.00)$ as shown in Table 1.

FLACC pain scores were significantly lower in Group BT as compared to Group B at $30 \mathrm{~min}, 1,4,8,12,24 \mathrm{~h}$ $(\mathrm{p}=0.000, \mathrm{p}=0.000, \mathrm{p}=0.000,0=0.000, \mathrm{p}=0.004$ and $\mathrm{p}=0.001$ respectively) as shown in Table 2 .

Side effects were found to be higher in Group B as compared to Group BT as shown in Table 3.

Table 1: Comparative postoperative sedation scores in both groups (Mean \pm SD)

\begin{tabular}{l|c|c|c}
$\begin{array}{c}\text { Sedation } \\
\text { scores }\end{array}$ & $\begin{array}{c}\text { Group B } \\
(\mathbf{N}=\mathbf{5 4})\end{array}$ & $\begin{array}{c}\text { Group BT } \\
(\mathbf{N}=\mathbf{5 4})\end{array}$ & p-value \\
\hline $30 \mathrm{~min}$ & $2.20 \pm 0.52$ & $1.00 \pm 0.0$ & 0.00 \\
\hline $1 \mathrm{~h}$ & $2.15 \pm 0.59$ & $1.00 \pm 0.0$ & 0.00 \\
\hline $4 \mathrm{~h}$ & $1.85 \pm 0.35$ & $1.00 \pm 0.0$ & 0.00 \\
\hline $8 \mathrm{~h}$ & $1.63 \pm 0.48$ & $1.00 \pm 0.0$ & 0.00 \\
\hline $12 \mathrm{~h}$ & $1.04 \pm 0.19$ & $1.00 \pm 0.00$ & 0.00 \\
\hline $24 \mathrm{~h}$ & $1.04 \pm 0.19$ & $1.00 \pm 0.00$ & 0.00 \\
\hline
\end{tabular}

Table 2: Comparative postoperative FLACC pain scores in both groups (Mean \pm SD)

\begin{tabular}{l|c|c|c}
$\begin{array}{c}\text { FLACC pain } \\
\text { scores }\end{array}$ & $\begin{array}{c}\text { Group B } \\
(\mathbf{N}=\mathbf{5 4})\end{array}$ & $\begin{array}{c}\text { Group BT } \\
(\mathbf{N}=\mathbf{5 4})\end{array}$ & p-value \\
\hline $30 \mathrm{~min}$ & $5.94 \pm 0.231$ & $1.00 \pm 0.00$ & 0.000 \\
\hline $1 \mathrm{~h}$ & $5.72 \pm 0.656$ & $1.00 \pm 0.00$ & 0.000 \\
\hline $4 \mathrm{~h}$ & $5.17 \pm 0.927$ & $1.00 \pm 0.00$ & 0.000 \\
\hline $8 \mathrm{~h}$ & $3.72 \pm 1.38$ & $1.00 \pm 0.00$ & 0.000 \\
\hline $12 \mathrm{~h}$ & $1.59 \pm 1.26$ & $1.00 \pm 0.00$ & 0.004 \\
\hline $24 \mathrm{~h}$ & $1.46 \pm 1.07$ & $1.00 \pm 0.00$ & 0.001 \\
\hline
\end{tabular}

Table 3: Comparison of side effects in both groups [n (\%)]

\begin{tabular}{l|c|c} 
Side effects & Group BT (N = 54) & Group B (N = 54) \\
\hline Motor weakness & $0(0 \%)$ & $1(0.9 \%)$ \\
\hline Urinary retention & $0(0 \%)$ & $2(3.7 \%)$ \\
\hline Vomiting & $2(3.7 \%)$ & $7(13 \%)$ \\
\hline
\end{tabular}

\section{DISCUSSION}

Caudal block is an epidural block and it is usually used as an adjunct to general anesthesia in children for low abdominal surgery. Caudal blockade is most frequently used with bupivacaine for smooth intraoperative analgesia and postoperative pain relief. ${ }^{11}$

Mean duration of surgery was significantly lower in $0.25 \%$ bupivacaine (Group B) as compared to combination of bupivacaine and tramadol (Group BT) $(\mathrm{p}=0.00)$. Mehmood et al. reported that mean duration of surgery was significantly lower in bupivacaine group as compared to placebo in general anesthesia among children. ${ }^{12}$

Laiq et al. reported that there was no significant difference in mean duration of surgery among bupivacaine-tramadol and levobupivacaine-tramadol groups $(30.3 \pm 1.2 \mathrm{~min}, 29.9 \pm 1.1 \mathrm{~min}, \mathrm{p}=0.145){ }^{13}$

In present study, mean sedation scores were significantly lower in bupivacaine-tramadol (Group BT) as compared to bupivacaine $0.25 \%$ (Group B) (p $=0.000$ ). Demiraran et al. reported that bupivacaine alone and combination of bupivacaine with tramadol had similar efficacy in general anesthesia in children $(\mathrm{p}=0.165) .{ }^{14}$ Prakash et al. reported that bupivacainetramadol had significantly higher sedation scores $(>2)$ as compared to bupivacaine with fentanyl. However, both groups did not had any side effects ( $p$ $=0.00) .{ }^{15}$

In present study, mean FLACC pain scores were significantly lower in bupivacaine-tramadol group as compared to bupivacaine group $(\mathrm{p}=0.000)$. Prosser et al. reported that bupivacaine- tramadol combination is associated with significant reduction in pain scores after $24 \mathrm{~h}$ of operation $(\mathrm{p}=0.001){ }^{16}$ Cook et al. reported a positive correlation in pain scores decrease and increased dose of bupivacainetramadol in general anesthesia $(\mathrm{r}=0.9, \mathrm{p}=0.03) .{ }^{17}$

In present study, bupivacaine alone is associated with high adverse effects as compared to bupivacainetramadol. More patients in Group B were affected with vomiting, urinary retention and motor weakness (13\%, 3.7\% and $0.9 \%$ respectively). Doctor et al. reported that most common side effects of bupivacaine were nausea, vomiting, hypotension, bradycardia, itching and respiratory depression. ${ }^{18}$ Another similar study reported that no adverse effects were found in comparison of bupivacaine $0.25 \%$ and a combination of bupivacaine-tramadol $(\mathrm{p}=0.165) \cdot{ }^{19}$ Khalid et al. reported that an addition of fentanyl to bupivacaine through caudal epidural administration leads to low level of motor blockade in children undergoing below umbilicus surgery. ${ }^{20}$

Khan et al. reported transient decrease in oxygen saturation upto $91 \%$ in few children along with vomiting undergoing surgery under general anesthesia. ${ }^{21}$ But in our study we did not note any desaturation. 
tramadol-bupivacaine for pediatric caudal bloc

\section{LIMITATIONS}

Our study had some limitations, e.g. our study was conducted at a single center with a small sample

\section{CONCLUSION}

Caudal bupivacaine plus tramadol confers high postoperative analgesic efficacy and reduced adverse effects as compared to bupivacaine alone in children undergone general anesthesia for lower abdominal surgery.

Conflict of interest: None declared by the authors

Authors' contribution:

NUN: Designing, data collection

MSB: Data analysis

HK: Manuscript writing

GM: Critical review data interpretation 
original article

\section{REFERENCES}

1. Acharya R, Jena SK, Samal S, Mishra SN. Postoperative analgesia in pediatrics patients through caudal block with bupivacaine and two different doses of fentanyl - A comparative study. J Evol Med Dent Sci. 2013;2(2):7568-74.

2. Patel D. Epidural analgesia for children. Contin Educ Anesth Crit Care Pain. 2016;6(1):63-6. [Free Full Text] DOI: 10.1093/bjaceaccp/mkl001

3. El Hamamsy $M$, Abd-Elrahman A, Abd-Elaziz Essa M, Zakaria D. Prolongation of caudal analgesia in pediatric surgery: Comparison between dexmedetomidine, clonidine, tramadol, and fentanyl. Kasr EL Einy Med J. 2018;14(2):1-10

4. Samad R, Shah TH. Comparison of caudal tramadol-bupivacaine and ketamine-bupivacaine for postoperative analgesia in children. $J$ Surg Pak Int. 2013;18(3):54-8. [Eree Full Text]

5. Shukla U, Prabhakar T, Malhotra $\mathrm{K}$. Postoperative analgesia in children when using clonidine or fentanyl with ropivacaine given caudally. J Anesthesiol Clin Pharmacol. 2011;27(2):205-10. [PubMed] [Free Full Text]

6. Nilsson S, Finnström B, Kokinsky E. The FLACC behavioral scale for procedural pain assessment in children aged 5-16 years. Paediatr Anesth. 2015;18(2):76774. [PubMed] DOI: $10.1111 / \mathrm{i} .1460$ $\underline{9592.2008 .02655 . X}$

7. Turan G, Yuksel G, Ormancý F. Preemptive analgesia with paracetamol and tramadol in pediatric adenotonsillectomy. J Anesth Clin Res. 2012 3:8. [Free Full Text]

8. Beyaz SG. Comparison of postoperative analgesic efficacy of caudal block versus dorsal penile nerve block with levobupivacaine for circumcision in children. Korean $\mathrm{J}$ Pain. 2015;24(3):31-5. [PubMed] [Free Full Text]

9. Ahmad S, Mohammad K, Ahmed M, Nazir I, Ommid M, Nabi V. Caudal analgesia in pediatric patients: Comparison between bupivacaine and ropivacaine. Internet J Anesthesiol. 2012 30:3. [Free Full Text]

10. Yasser M, Khairat M. A comparison of caudally administered single dose bupivacaine and bupivacainetramadol combination for postoperative analgesia in children. JK Sci. 2016;6(3):19-22.

11. Campbell FA, Yentis SM, Fear DW, Bissonnette B. Analgesic efficacy and safety of a caudal bupivacainefentanyl mixture in children. Can J Anesth. 1992;39(2):6614. [PubMed] DOI: $\underline{10.1007 /}$ BF0300822

12. Mehmood MT, Ahmed J, Haque SN. Caudal bupivacaine tramadol low dose combination for post-operative analgesia in pediatric patients. Pak J Surg. 2017;25(3):88-92.

13. Laiq N, Khan MN, Tahmeedullah, Gandapur YK, Khan S. Comparison of caudal bupivacaine and bupivacainetramadol for postoperative analgesia in children undergoing hypospadias surgery. J Coll Physicians Surg Pak. 2009;19(11):678-81. [PubMed] DOI: $11.2009 /$ JCPSP.678681

14. Demiraran Y, Kocaman B, Akman RY. A comparison of the postoperative analgesic efficacy of single-dose epidural tramadol versus morphine in children. Br J Anesth. 2005;95(4):510 3. [PubMed] DOI: 10.1093/bja/aei214

15. Prakash S, Tyagi R, Gogia AR, Singh R, Prakash S. Efficacy of three doses of tramadol with bupivacaine for caudal analgesia in paediatric inguinal herniotomy. $\mathrm{Br}$ J Anesth. 2006;97(3):3858. [PubMed] DOI: $\underline{0.1093 / \mathrm{bja} / \mathrm{ael} 155}$

16. Prosser DP, Davis A, Booker PD, Murray A. Caudal tramadol for postoperative analgesia in pediatric hypospadias surgery. Br J Anesth. 1997;79(3):2936. [PubMed]

17. Cook B, Doyle E. The use of additives to local Anesthetic solutions for caudal epidural blockade. Paediatr Anesth. 1996;6(5):353-9. [PubMed]

18. Doctor TP, Dalwadi DB, Abraham L, Shah N, Chadha IA, Shah BJ. Comparison of ropivacaine and bupivacaine with fentanyl for caudal epidural in pediatric surgery. Anesth Essays Res. 2013;7(1):212-5. [PubMed] [Free Full Text] DOI: 10.4103/02591162.118965

19. Kawaraguchi $\mathrm{Y}$, Otomo T, Ota C, Uchida N, Taniguchi A, Inoue S. A prospective, double-blind, randomized trial of caudal block using ropivacaine $0.2 \%$ with or without fentanyl 1 microg $\mathrm{kg}$-1 in children. $\mathrm{Br}$ J Anesth. 2006;97(6):85861. [PubMed]

20. Khalid A, Siddiqui Zafar S, Haider S, Aftab S. Single dose caudal tramadol with bupivacaine and bupivacaine alone in pediatric inguino-scrotal surgeries. J Coll Physicians Surg Pakistan. 2007;17:519-22. [PubMed]

21. Khan S, Memon MI. Comparison of caudal bupivacaine and bupivacaine tramadol for post-operative analgesia in children with hypospadias repair. J Coll Physicians Surg Pakistan. 2008;18:601-4 [PubMed] 